\title{
A Novel Partial Duplication of ZEB2 and Review of ZEB2 Involvement in Mowat-Wilson Syndrome
}

\author{
Adrianne L. Baxter ${ }^{a}$ Jay L. Vivian ${ }^{b} \quad$ R. Tanner Hagelstrom ${ }^{d}$ Waheeda Hossain ${ }^{c}$ \\ Wendy L. Golden ${ }^{\mathrm{a}} \quad$ E. Robert Wassman ${ }^{\mathrm{a}}$ Rena J. Vanzo ${ }^{\mathrm{a}}$ Merlin G. Butler ${ }^{\mathrm{c}}$ \\ a Lineagen, Inc., Salt Lake City, UT, Departments of ${ }^{b}$ Pathology and Laboratory Medicine and ${ }^{\mathrm{C} P}$ sychiatry and \\ Behavioral Sciences and Pediatrics, University of Kansas Medical Center, Kansas City, KS, and d Human Genetics \\ Laboratory, University of Nebraska Medical Center, Omaha, NE, USA
}

\section{Established Facts}

- Mowat-Wilson syndrome is caused by heterozygous mutation of ZEB2.

- Over 180 different disease-causing mutations have been reported, including point mutations, deletions, and large chromosomal rearrangements.

\section{Novel Insights}

- We present the first reported case of Mowat-Wilson syndrome caused by a partial duplication of ZEB2.

- This case expands the types of mutations that can cause Mowat-Wilson syndrome and highlights the significance of partial gene duplications in the pathogenesis of genetic conditions.

\section{Keywords}

Mowat-Wilson syndrome · Partial duplication · ZEB2

\section{Abstract}

Mowat-Wilson syndrome is a rare genetic condition characterized by intellectual disability, structural anomalies, and dysmorphic features. It is caused by haploinsufficiency of the ZEB2 gene in chromosome 2q22.3. Over 180 distinct muta-

\section{KARGER}

๑) 2017 S. Karger AG, Basel

E-Mail karger@karger.com

www.karger.com/msy tions in ZEB2 have been reported, including nonsense and missense point mutations, deletions, and large chromosomal rearrangements. We report on a 14-year-old female with a clinical diagnosis of Mowat-Wilson syndrome. Chromosomal microarray identified a novel de novo 69-kb duplication containing exons 1 and 2 of the ZEB2 gene. Sequence analysis identified no other variants in this gene. This is the first report of a partial duplication of the ZEB2 gene resulting in Mowat-Wilson syndrome.

(c) 2017 S. Karger AG, Basel
Merlin G. Butler, MD, PhD

Departments of Psychiatry and Behavioral Sciences and Pediatrics University of Kansas Medical Center

3901 Rainbow Blvd., MS 4015, Kansas City, KS 66160 (USA)

E-Mail mbutler4@kumc.edu 
Mowat-Wilson syndrome (MWS; OMIM 235730) is a rare genetic syndrome seen in 1:50,000-70,000 individuals [Mowat and Wilson, 2010]. First described by Mowat et al. in 1998, it is characterized by intellectual disability, structural anomalies, and dysmorphic features [Mowat et al., 1998; Adam et al., 2013]. Intellectual disability is typically in the moderate to severe range, expressive speech is particularly impaired, and about $70-75 \%$ of affected individuals have seizures [Wilson et al., 2003; Garavelli et al., 2009; Cordelli et al., 2013]. Common structural abnormalities include Hirschsprung disease and defects of the heart, genitourinary system, eyes, and brain (anomalies of corpus callosum, hippocampal abnormalities, enlargement of cerebral ventricles, white matter abnormalities, large basal ganglia, cortical and cerebellar malformations) [Adam et al., 2006; Garavelli and Mainardi, 2007; Ariss et al., 2012; Bourchany et al., 2015; Coyle and Puri, 2015; Garavelli et al., 2016]. Distinctive facial features include hypertelorism, broad medial eyebrows, low-hanging columella, prominent or pointed chin, and uplifted earlobes with a central depression [Zweier et al., 2005]. Additionally, individuals with this condition may have growth delay, microcephaly, and musculoskeletal anomalies [Mowat et al., 2003; Adam et al., 2006; Cordelli et al., 2013]. Birth weight and length are typically normal.

MWS is due to dominantly expressed, heterozygous mutations of the zinc finger E box-binding homeobox 2 gene (ZEB2, also called ZFHX1B or SIP1) located on chromosome 2q22.3 [Cacheux et al., 2001; Wakamatsu et al., 2001]. ZEB2 has 10 exons (exon 1 is noncoding) and is about $165 \mathrm{~kb}$ in size [Wakamatsu et al., 2001]. Mutations leading to MWS are thought to result in truncated or absent protein products [Mowat et al., 2003].

More than 180 different disease-causing mutations of ZEB2 have been reported [Ghoumid et al., 2013]. Loss-offunction point mutations account for $70-80 \%$ of MWS diagnoses, while deletions (ranging in size from exonic to multiple contiguous genes) represent another 15-20\% [Garavelli and Mainardi, 2007; Saunders et al., 2009]. In rare cases (up to $2 \%$ of affected individuals), large chromosomal rearrangements, such as translocations, are identified [Adam et al., 2007]. A few individuals with MWS who harbor missense mutations in ZEB2 have been reported [Heinritz et al., 2006; Dastot-Le Moal et al., 2007; Ghoumid et al., 2013; Wenger et al., 2014]. There is also a small proportion of individuals who have a clinical diagnosis of MWS but in whom a ZEB2 mutation is not identified.

We present a case of a 14-year-old female with a de novo 69-kb duplication encompassing part of ZEB2. Spe- cifically, the duplication contained exons 1 and 2. She presented with developmental delays, multiple congenital anomalies, and a clinical diagnosis of MWS based on her medical history, physical features, and clinical presentation. She represents the first published case of an individual with a novel partial duplication of ZEB2 resulting in MWS.

\section{Patient and Methods}

\section{Clinical Report}

Our patient was first evaluated genetically at age 14 years at which time she presented with multiple health problems, intellectual disability, and a clinical diagnosis of MWS made at 2 years of age. At age 14 years, her height was $148 \mathrm{~cm}$ ( $<3 \mathrm{rd}$ centile), weight was $41.4 \mathrm{~kg}$ (5th centile), and her head circumference was $49.3 \mathrm{~cm}$ ( $<3$ rd centile). Her BMI was 18.9. Congenital anomalies present at birth included cardiac defects (atrial septal defect, patent ductus arteriosus, and a bicuspid aortic valve), midline cutaneous pigment abnormalities, and a sacral dimple. Breast and bottle feeding were unsuccessful, so a nasogastric tube and, later, a G-tube were placed. Shortly after birth, she was diagnosed with global developmental delay and Hirschsprung disease. She has had 2 pull-through surgeries and one colostomy with $47 \mathrm{~cm}$ of her colon removed. She currently utilizes laxatives and a predigestive formula for treatment. She has a neurogenic bladder, kidney reflux, incontinence, and a tethered cord (for which surgery was recently performed). A head MRI showed agenesis of the corpus callosum and 3 frontal lobe cysts which diminished in size on repeated brain imaging studies. Seizures developed at age 2 years and are currently medically controlled. At age 10 years, she began consuming food by mouth but did not chew normally. She drinks liquid from a straw.

At age 14 years, her inner canthal distance was $3.7 \mathrm{~cm}(>97 \mathrm{th}$ centile); outer canthal distance was $8.8 \mathrm{~cm}$ (40th centile), and her ear length was $5.5 \mathrm{~cm}$ (20th centile). Hand length was $15.7 \mathrm{~cm}$ (3rd centile) and middle finger length was $6.6 \mathrm{~cm}$ (5th centile). She had a square face with medial flare to her eyebrows, a depressed and wide nasal root, hypertelorism with downslanting palpebral fissures, ptosis, strabismus, a short prominent nose with a broad nasal tip, prominent vertical philtral ridges with a short philtrum, full everted upper and lower lips with thinning of upper lip laterally, and downturned corners of the mouth with prognathism. Her ears were posteriorly rotated and fleshy with attached lobes and mild uplifting of the right earlobe (see Fig. 1). The pupils were round and equal in size without scleral icterus. There was a normal range of motion of the neck. The cardiopulmonary system was within normal limits without a heart murmur, rhythm irregularity, or abnormal breath sounds. Her abdomen was soft with no masses or hernias. Major joints had a normal range of motion, but she displayed increased reflexes and tone of both upper and lower body segments as well as poor coordination with a wide-based gait. She walked at age 5 years. She bruises easily and has a history of low platelet counts, first identified at age 10 years. She did not require transfusions but continues to have low platelet count. Cutis marmorata was noted. She was diagnosed with osteopenia and treated for hypothyroidism since age 10 years. She had not begun menstrual cycles.
212

Mol Syndromol 2017;8:211-218 DOI: $10.1159 / 000473693$
Baxter/Vivian/Hagelstrom/Hossain/ Golden/Wassman/Vanzo/Butler 

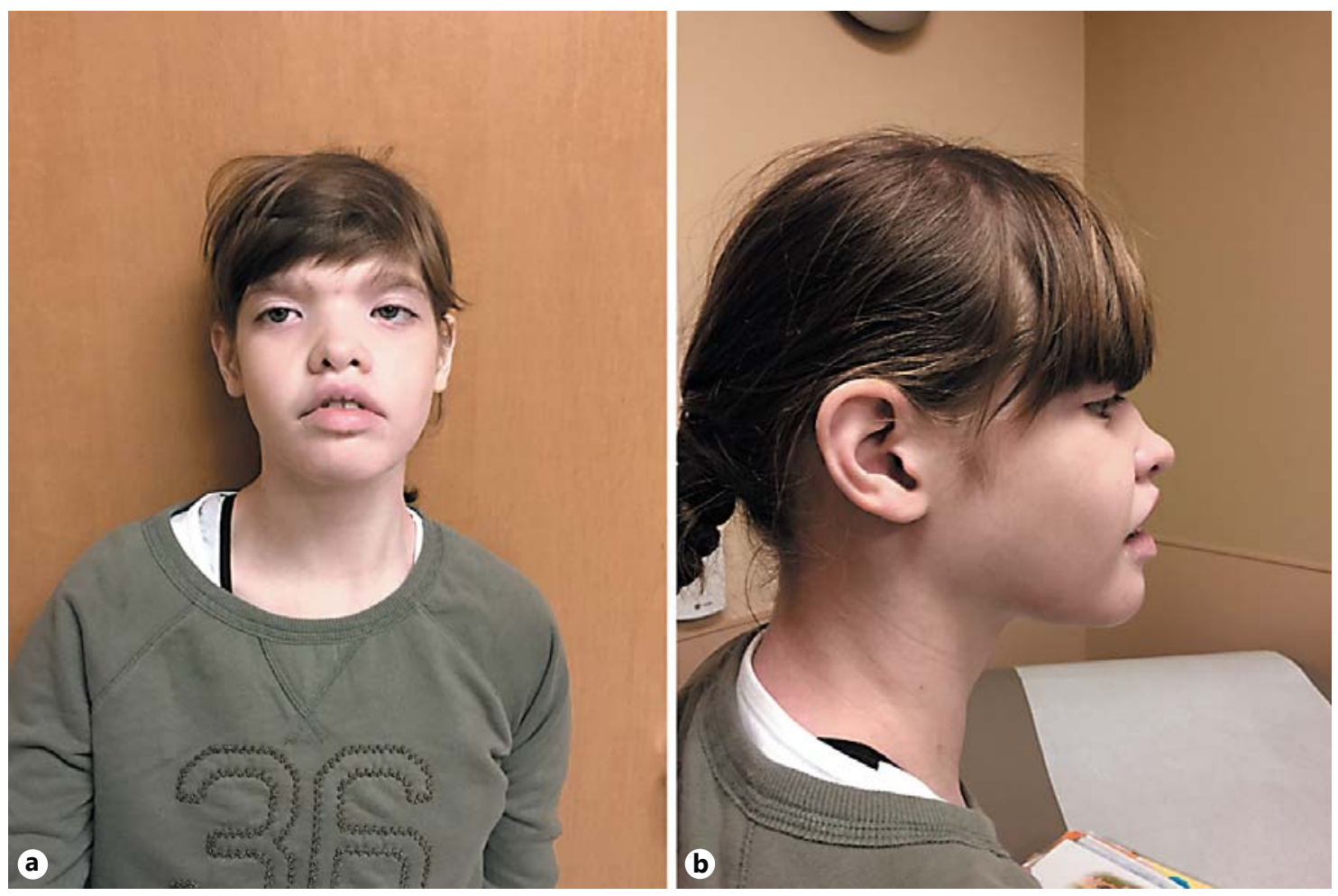

Fig. 1. Facial frontal (a) and profile (b) views of our patient at age 14 years showing medial flare of the eyebrows, depressed and wide nasal root, hypertelorism with downslanting palpebral fissures, ptosis, short prominent nose with a broad nasal tip, short philtrum, full everted lips, downturned corners of mouth, and posteriorly rotated ears with attached earlobes.

A 3-generation pedigree found our patient's 20-year-old full sister and father are alive and well, and her mother has a history of arthritis, a positive antinuclear antibody titer, irritable bowel syndrome, and melanoma. There is a positive family history of hemophilia type A in a paternal uncle. Consanguinity was denied. Family history is otherwise unremarkable, and no other family members have MWS.

\section{Chromosomal Microarray Analysis}

Genetic testing was performed by Lineagen, Inc. (Salt Lake City, UT, USA) using a custom $2.8 \mathrm{M}$ probe whole genome chromosome microarray built upon the Affymetrix CytoScanHD ${ }^{\circledR}$ platform (Affymetrix, Santa Clara, CA, USA) with 88,435 additional probes designed to optimize testing for individuals with developmental delay/intellectual disability and/or autism spectrum disorder. The microarray contains both copy number and SNP probes. Coverage for ZEB2 included 380 probes with an average probe spacing $<500 \mathrm{bp}$. The Affymetrix Chromosome Analysis Suite (ChAS) software was used for copy number detection using standard protocols (Affymetrix). The proband's whole genome was evaluated by chromosomal microarray analysis (CMA) for clinical diagnostic testing. Parental DNA was subsequently submitted, and only the region of interest was evaluated by CMA on a research basis.

ZEB2 Partial Duplication in

Mowat-Wilson Syndrome
ZEB2 Gene Sequence Analysis

This patient's genomic DNA specimen was used for next-generation sequencing. DNA was sheared into small fragments that were end-ligated oligo-adapters, target-enriched for coding exons along with $10 \mathrm{bp}$ of flanking intronic sequence in ZEB2 (RefSeq NM_014795.3), and amplified by PCR and sequenced using bridge amplification. This targeted gene sequencing strategy interrogates the coding regions and splice site junctions of $Z E B 2$ only.

\section{Results}

CMA identified a novel 69-kb duplication of 2q22.3 including ZEB2, arr[hg19] 2q22.3(145,218,807$145,287,401) \times 3$, encompassing exons 1 and 2 as well as intron 1 and part of intron 2 (see Fig. 2, 3). ZEB2 was the only gene that was partially included in this duplication. Next-generation sequencing of $Z E B 2$, performed to rule out the presence of sequence variants contributing to the patient's phenotype, identified no ZEB2 sequence variants. Parental CMA assessing only the region of interest on chromosome 2 did not identify any CNVs, indicating that the patient's duplication is de novo.

Mol Syndromol 2017;8:211-218 


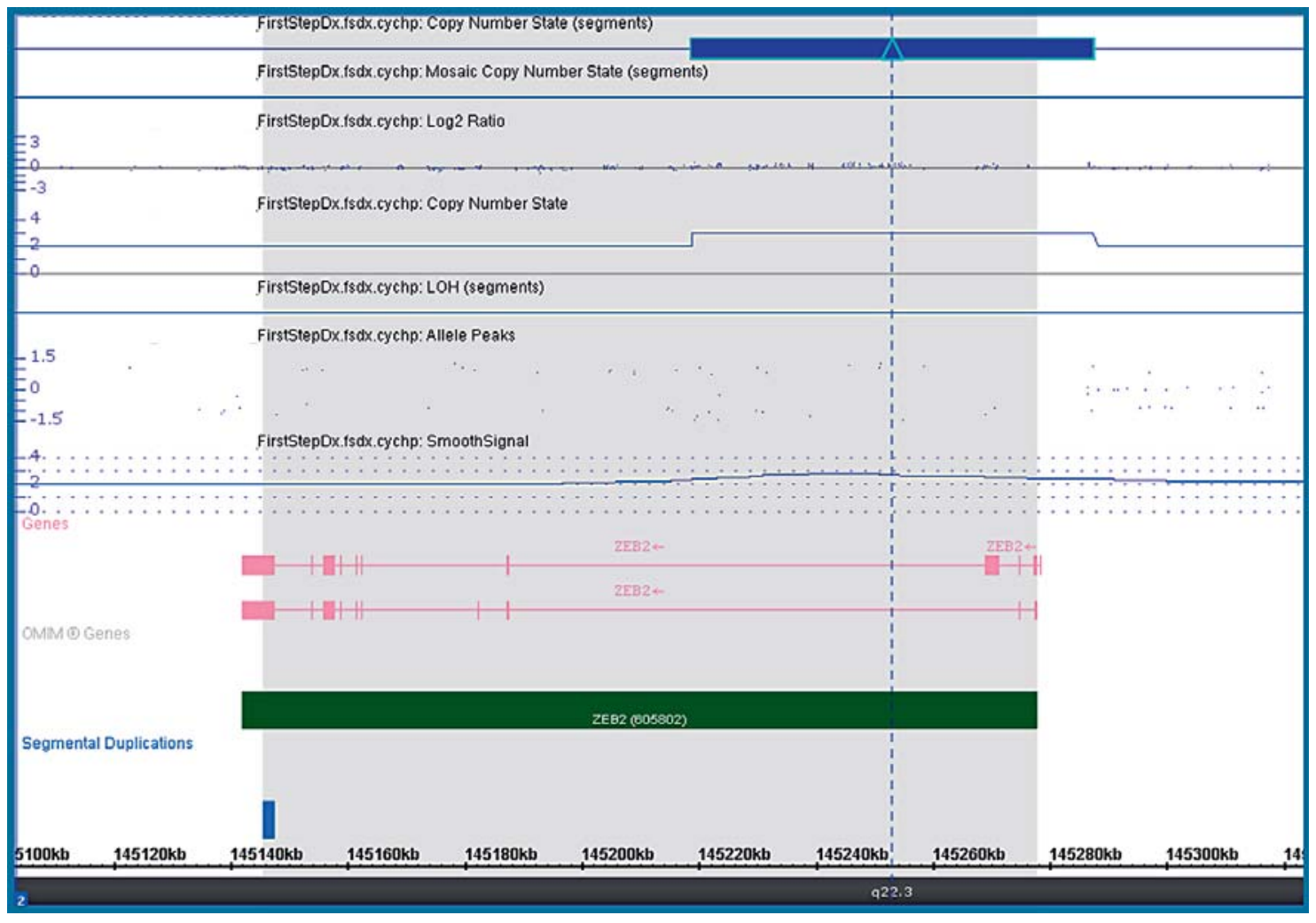

Fig. 2. Chromosomal microarray analysis showing the 69-kb interstitial duplication of chromosome 2q22.3 (chr2: $145,218,807-145,287,401$ with hg build 19) found in our patient performed by Lineagen, Inc. ZEB2 is partially duplicated in this region.

\section{Discussion}

A variety of mutations have been described in individuals with MWS. The majority of individuals with MWS have point mutations within ZEB2 that cause protein truncation and, therefore, loss of function [Dastot-Le Moal et al., 2007]. Within this cohort, germline mosaicism has been suggested and low-level somatic mosaicism reported. The estimated recurrence is $1 \%$ when parents test negative for a familial mutation [Zweier et al., 2005]. Additionally, another 15-20\% of individuals with MWS have exonic or complete gene deletions of ZEB2 [Adam et al., 2013].

Most features seen in our patient, including microcephaly, seizures, distinctive facies, and Hirschsprung disease, are consistent with loss or altered function of ZEB2. However, chromosomal microarray cannot in itself determine if a partial duplication as observed in this case has disrupted gene function. Interpretation of duplications is always challenging as they may not alter gene function or could lead to increased dosage, gene disrup- tion, or novel function due to gene fusion [Newman et al., 2015]. This has been demonstrated to be true for duplications of ZEB2 as well.

Phenotypic consequences from increased dosage of ZEB2 have been suggested (see Fig. 4; Table 1). Yuan et al. [2015] reported a boy with a de novo 2.9-Mb triplication/duplication involving chromosome $2 \mathrm{q} 22.3$ which encompassed the entire ZEB2 gene as well as GTDC1, TEX41, and part of ARHGAP15. This boy presented with hypotonia, cognitive impairment, behavioral abnormalities, dysmorphic features, and an atrial septal heart defect. While his severe speech impairment and open-mouth appearance are commonly reported in those with MWS, his facial features were significantly different than those seen in MWS.

A duplication of an overlapping 2.1-Mb region was recently reported by Mak et al. [2016]. Just as the duplication reported by Yuan et al. [2015], this duplication fully included ZEB2 as well as GTDC1, TEX41, and part of ARHGAP15. This 32-year-old woman presented with tetralogy of Fallot, patent foramen ovale, mild intellectual 


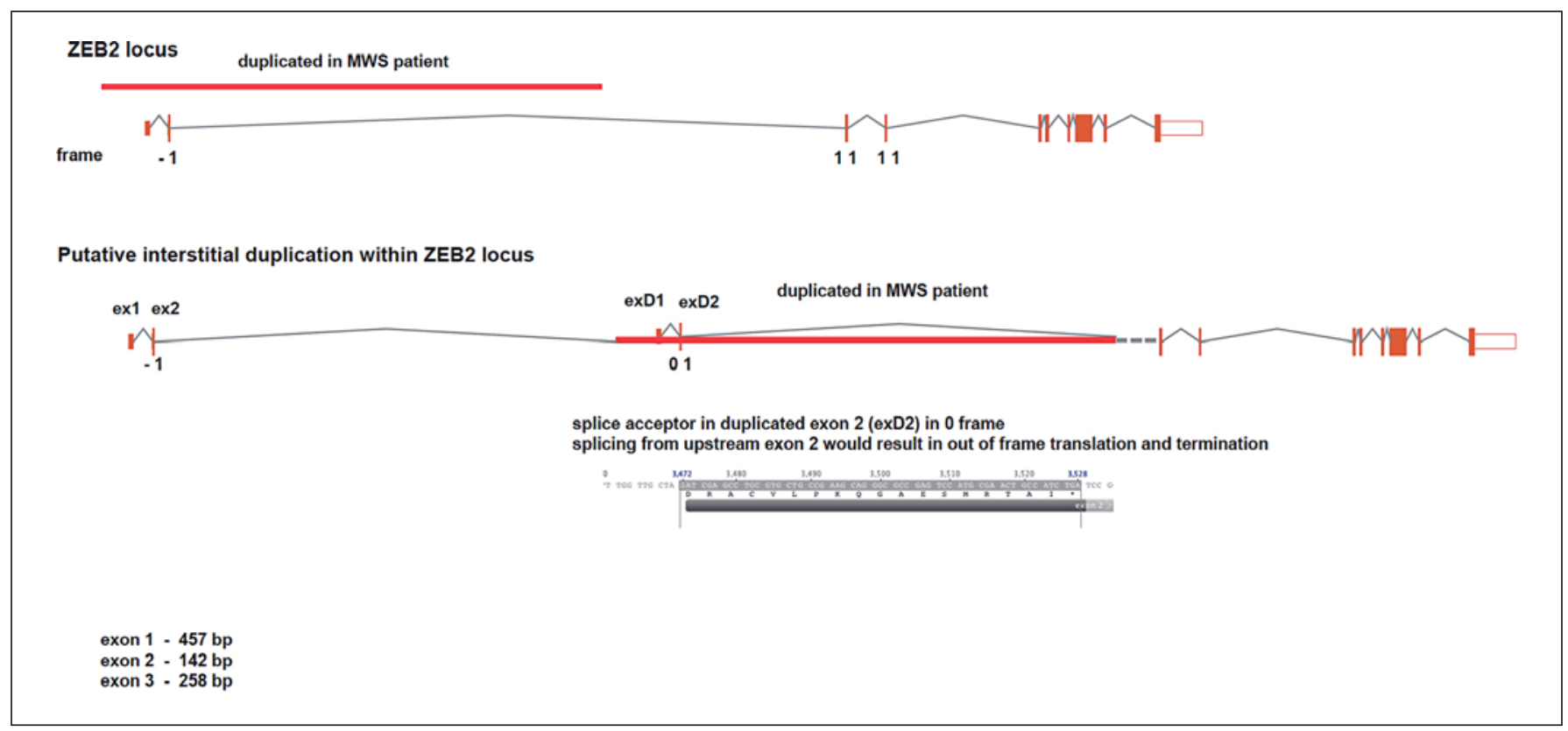

Fig. 3. Diagram of the putative interstitial duplication within the ZEB2 locus encompassing exons 1 and 2 and intron 1 with part of intron 2 identified in our patient with Mowat-Wilson syndrome identified with high-resolution chromosomal microarray analysis.

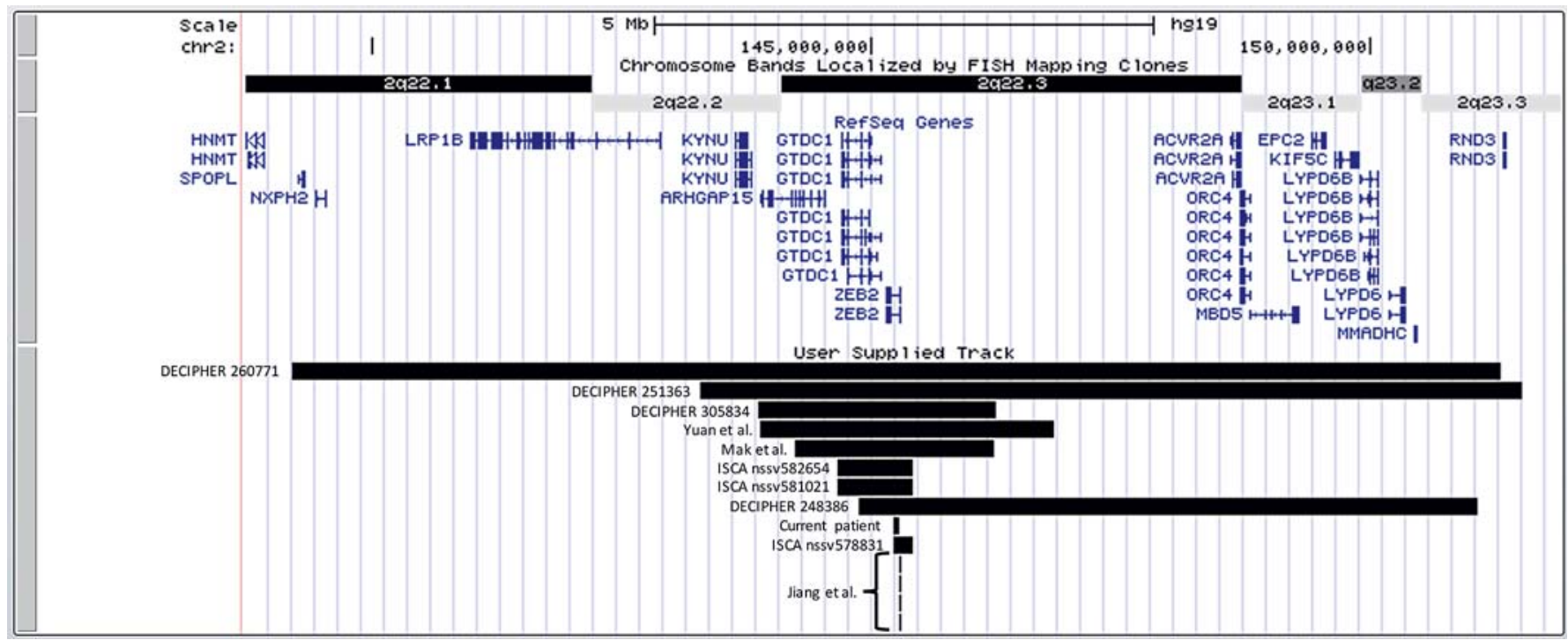

Fig. 4. UCSC Genome Browser view showing the current patient and previously reported copy number gains involving ZEB2.

disability, adjustment disorder, dysmorphic features, and a hypernasal voice. Notably, her dysmorphic features were not similar to those seen in MWS.

Seven other individuals with copy number gains involving part or all of $Z E B 2$ were identified within the

ZEB2 Partial Duplication in

Mowat-Wilson Syndrome
DECIPHER (https://decipher.sanger.ac.uk) [Firth et al., 2009; Swaminathan et al., 2012] and ISCA (International Standards for Cytogenomic Arrays) clinical genomic resource databases (http://dbsearch.clinicalgenome.org). Direct comparisons between these previous reports and

Mol Syndromol 2017;8:211-218

DOI: $10.1159 / 000473693$ 


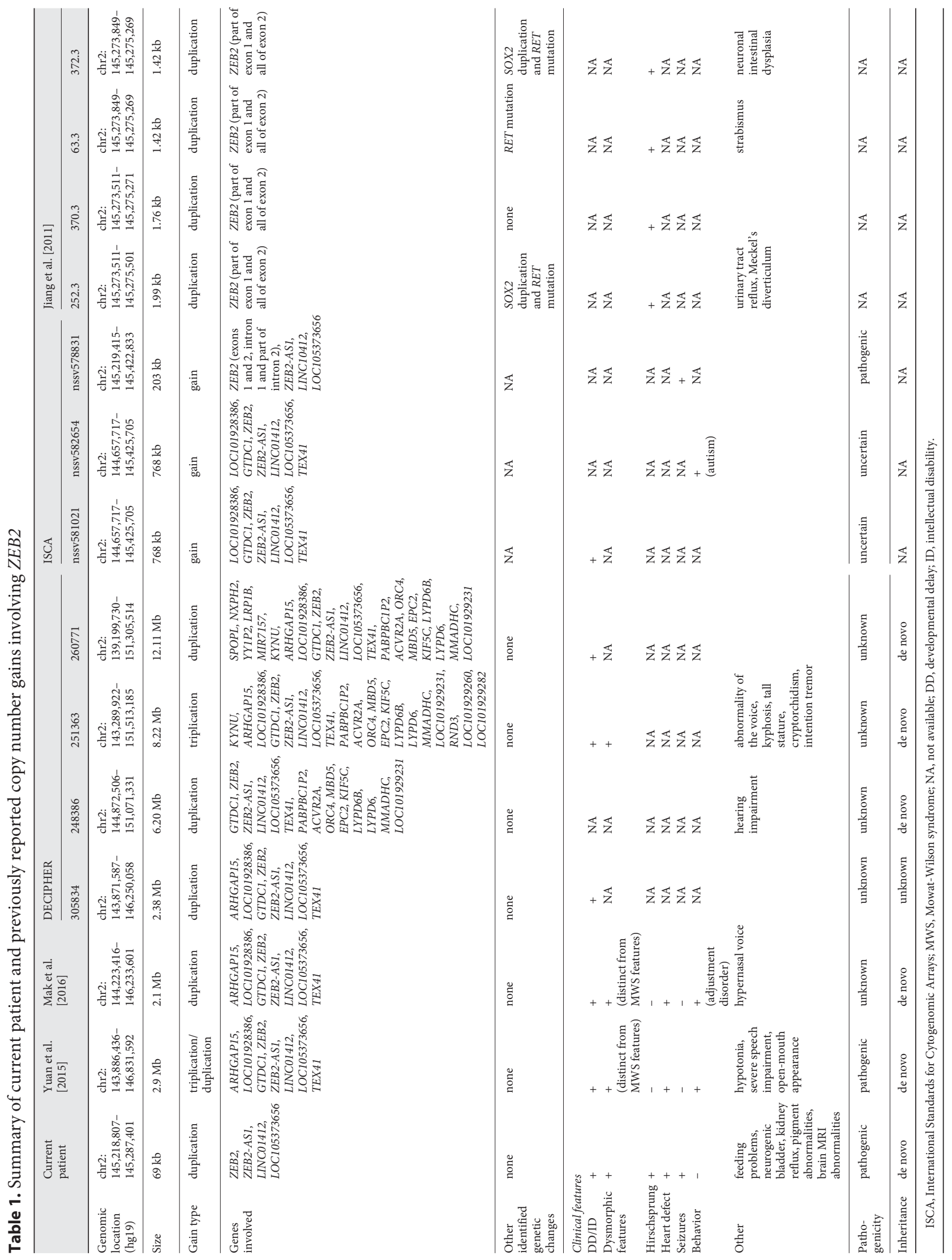


the current patient may be difficult as most of the previous duplications are much larger and contained additional genes. Six of these gains were de novo and 1 did not have parental testing information available. Six of these individuals had clinical features that overlapped with those seen in MWS (intellectual disability, developmental delay, dysmorphic features, multiple congenital anomalies, and seizures). One patient presented only with hearing impairment (DECIPHER 238286).

Also, 1 patient (nssv578831) found in the ISCA database had a reportedly pathogenic de novo $203-\mathrm{kb}$ duplication which included exons 1 and 2 and intron 1 with part of intron 2 within ZEB2 (larger but similar duplication region as seen in our patient; see Fig. 3). This patient was reported to have seizures. It is unknown if the patient had or developed any other features of MWS that were not reported in the ISCA database.

Additionally, Jiang et al. [2011] described 4 unrelated individuals with Hirschsprung disease who had 2q22.3 duplications (ranging from 1.42-1.99 kb in size) involving part of exon 1 and all of exon 2 . Three of these individuals had additional physical anomalies, but 1 individual had a mutation in RET and 2 had a SOX2 duplication with a mutation in $R E T$ that likely contributed to their clinical features. These reports indicate that partial duplications of ZEB2 likely contribute to pathogenesis of Hirschsprung disease, one of the core features of MWS.

All of these previously reported cases demonstrate that both partial and full duplications of ZEB2 can be pathogenic, resulting in abnormal clinical features. Previous reports of partial duplications of $Z E B 2$ have been identified in individuals with some clinical features of MWS, but none of these previously reported individuals were actually specifically diagnosed of MWS or presented with all of the key features of this condition.
Causative partial gene duplications have been reported in several other conditions that are typically caused by point mutations. These include neurofibromatosis type 1 , Rubinstein-Taybi syndrome, Cornelia de Lange syndrome, and Kleefstra syndrome [Roelfsema et al., 2005; Russo et al., 2012; Nemethova et al., 2013; Schwaibold et al., 2014]. These cases provide evidence that a partial duplication of $Z E B 2$ could similarly result in a haploinsufficient condition.

In conclusion, our patient represents the first report of a partial duplication of ZEB2 in an individual with an established clinical diagnosis of MWS. This highlights the significance of partial gene duplications in the pathogenesis of genetic conditions and expands the types of mutations that can cause MWS.

\section{Acknowledgments}

The authors thank the patient and her parents for their participation in this publication. We also thank Pat Rushton for providing ChAS images, Megan Martin for her guidance on the manuscript, and Karen Ho for useful discussions and manuscript review. We acknowledge support from the National Institute of Child Health and Human Development (NICHD) grant HD02528.

\section{Statement of Ethics}

Informed consent was obtained for this report from the parents of the patient in accordance with institutional standards for the protection of human research subjects.

\section{Disclosure Statement}

The authors have no conflicts of interest to declare.

\section{References}

Adam MP, Schelley S, Gallagher R, Brady AN Barr K, et al: Clinical features and management issues in Mowat-Wilson syndrome. Am J Med Genet A 140:2730-2741 (2006).

Adam MP, Conta J, Bean LJH: Mowat-Wilson syndrome, in Pagon RA, Adam MP, Ardinger $\mathrm{HH}$, Wallace SE, Amemiya A, et al (eds): GeneReviews $^{\circledR} \quad$ [Internet] (University of Washington, Seattle 1993-2017). Initial posting: 2007 Mar 28; last update: 2013 Nov 26.

Ariss M, Natan K, Friedman N, Traboulsi EI: Ophthalmologic abnormalities in MowatWilson syndrome and a mutation in ZEB2. Ophthalmic Genet 33:159-60 (2012).
Bourchany A, Giurgea I, Thevenon J, Goldenberg A, Morin G, et al: Clinical spectrum of eye malformations in four patients with MowatWilson syndrome. Am J Med Genet A 167: 1587-1592 (2015).

Cacheux V, Dastot-Le Moal F, Kääriäinen $H$, Bondurand N, Rintala R, et al: Loss-of-function mutations in SIP1 Smad interacting protein 1 results in a syndromic Hirschsprung disease. Hum Mol Genet 10:1503-1510 (2001).

Cordelli DM, Garavelli L, Savasta S, Guerra A, Pellicciari A, et al: Epilepsy in Mowat-Wilson syndrome: delineation of the electroclinical phenotype. Am J Med Genet A 161A:273-284 (2013).

Coyle D, Puri P: Hirschsprung's disease in children with Mowat-Wilson syndrome. Pediatr Surg Int 31:711-717 (2015).

Dastot-Le Moal F, Wilson M, Mowat D, Collot N, Niel F, Goossens M: ZFHX1B mutations in patients with Mowat-Wilson syndrome. Hum Mutat 28:313-321 (2007).

Firth HV, Richards SM, Bevan AP, Clayton S, Corpas M, et al: DECIPHER: Database of Chromosomal Imbalance and Phenotype in Humans Using Ensembl Resources. Am J Hum Genet 84:524-533 (2009).
ZEB2 Partial Duplication in

Mowat-Wilson Syndrome
Mol Syndromol 2017;8:211-218 DOI: $10.1159 / 000473693$ 
Garavelli L, Mainardi PC: Mowat-Wilson syndrome. Orphanet J Rare Dis 2:42 (2007).

Garavelli L, Zollino M, Mainardi PC, Gurrieri F, Rivieri F, et al: Mowat-Wilson syndrome: facial phenotype changing with age: study of 19 Italian patients and review of the literature. Am J Med Genet A 149A:417-426 (2009).

Garavelli L, Ivanovski I, Caraffi SG, Santodirocco D, Pollazzon M, et al: Neuroimaging findings in Mowat-Wilson syndrome: a study of 54 patients. Genet Med, Epub ahead of print (2016).

Ghoumid J, Drevillon L, Alavi-Naini SM, Bondurand $\mathrm{N}$, Rio $\mathrm{M}$, et al: ZEB2 zinc-finger missense mutations lead to hypomorphic alleles and a mild Mowat-Wilson syndrome. Hum Mol Genet 22:2652-2661 (2013).

Heinritz W, Zweier C, Froster UG, Strenge S, Kujat A, et al: A missense mutation in the $Z F$ $H X 1 B$ gene associated with an atypical Mowat-Wilson syndrome phenotype. Am J Med Genet A 140:1223-1227 (2006).

Jiang Q, Ho YY, Hao L, Nichols Berrios C, Chakravarti A: Copy number variants in candidate genes are genetic modifiers of Hirschsprung disease. PLoS One 6:e21219 (2011).

Mak CCY, Chow PC, Liu APY, Chan KYK, Chu YWY, et al: De novo large rare copy-number variations contribute to conotruncal heart disease in Chinese patients. NPJ Genom Med 1:16033 (2016).

Mowat DR, Wilson MJ: Mowat-Wilson syndrome, in Cassidy SB, Allanson JE (eds): Management of Genetic Syndromes (John Wiley and Sons, New York 2010).
Mowat DR, Croaker GD, Cass DT, Kerr BA, Chaitow J, et al: Hirschsprung disease, microcephaly, mental retardation, and characteristic facial features: delineation of a new syndrome and identification of a locus at chromosome 2q22-q23. J Med Genet 35:617-623 (1998).

Mowat DR, Wilson MJ, Goossens M: MowatWilson syndrome. J Med Genet 40:305-310 (2003).

Nemethova M, Bolcekova A, Ilencikova D, Durovcikova $\mathrm{D}$, Hlinkova $\mathrm{K}$, et al: Thirty-nine novel neurofibromatosis 1 (NF1) gene mutations identified in Slovak patients. Ann Hum Genet 77:364-379 (2013).

Newman S, Hermetz KE, Weckselblatt B, Rudd MK: Next-generation sequencing of duplication CNVs reveals that most are tandem and some create fusion genes at breakpoints. Am J Hum Genet 96:208-220 (2015).

Roelfsema JH, White SJ, Ariyürek Y, Bartholdi D, Niedrist D, et al: Genetic heterogeneity in Rubinstein-Taybi syndrome: mutations in both the $C B P$ and EP300 genes cause disease. Am J Hum Genet 76:572-580 (2005).

Russo S, Masciadri M, Gervasini C, Azzollini J, Cereda $\mathrm{A}$, et al: Intragenic and large NIPBL rearrangements revealed by MLPA in Cornelia de Lange patients. Eur J Hum Genet 20: 734-741 (2012).

Saunders CJ, Zhao W, Ardinger HH: Comprehensive ZEB2 gene analysis for Mowat-Wilson syndrome in a North American cohort: a suggested approach to molecular diagnostics. Am J Med Genet A 149A:2527-2531 (2009).
Schwaibold EM, Smogavec M, Hobbiebrunken E, Winter L, Zoll B, et al: Intragenic duplication of EHMT1 gene results in Kleefstra syndrome. Mol Cytogenet 7:74 (2014).

Swaminathan GJ, Bragin E, Chatzimichali EA, Corpas M, Bevan AP, et al: DECIPHER: webbased, community resource for clinical interpretation of rare variants in developmental disorders. Hum Mol Genet 21:R37-44 (2012).

Wakamatsu N, Yamada Y, Ono T, Nomura N, Taniguchi $\mathrm{H}$, et al: Mutations in SIP1, encoding Smad interacting protein-1, cause a form of Hirschsprung disease. Nat Genet 27:369370 (2001).

Wenger TL, Harr M, Ricciardi S, Bhoj E, Santani A, et al: CHARGE-like presentation, craniosynostosis and mild Mowat-Wilson syndrome diagnosed by recognition of the distinctive facial gestalt in a cohort of 28 new cases. Am J Med Genet A 164A:2557-2566 (2014).

Wilson M, Mowat D, Dastot-Le Moal F, Cacheux V, Kääriäinen $\mathrm{H}$, et al: Further delineation of the phenotype associated with heterozygous mutation in ZFHX1B. Am J Med Genet 119A:257-265 (2003).

Yuan H, Zhang L, Chen M, Zhu J, Meng Z, Liang $\mathrm{L}$ : A de novo triplication on $2 \mathrm{q} 22.3$ including the entire ZEB2 gene associated with global developmental delay, multiple congenital anomalies and behavioral abnormalities. Mol Cytogenet 8:99 (2015).

Zweier C, Thiel CT, Dufke A, Crow YJ, Meinecke $\mathrm{P}$, et al: Clinical and mutational spectrum of Mowat-Wilson syndrome. Eur J Med Genet 48:97-111 (2005). 